\title{
Comparison of artificial neural network models of categorized daily electric load
}

\author{
Vildan Evren ${ }^{1}$, Ilker Ali Ozkan ${ }^{2}$ \\ ${ }^{1}$ Selcuk University, Selcuk University, The Degree of Master of Science of Information Technologies Engineering, 42000 \\ Konya, Turkey, evrenvildannn@gmail.com, ORCID: 0000-0003-1654-3731 \\ ${ }^{2}$ Computer Engineering Department, Faculty of Technology, Selcuk University, 42000 Konya, Turkey, \\ ilkerozkan@selcuk.edu.tr, ORCID: 0000-0002-5715-1040
}

\section{A B S T R A C T}

The efficient operation of power systems and future planning, electricity load forecast is very important. Load estimation is based on predicting future electric load by examining past conditions. Short-term load prediction plays a decisive role in the load sharing of power plants. It also allows to overcome shortcomings caused by sudden load increases and power plant losses. Weather conditions are effective in short-term electrical load estimation. Daily or hourly electricity consumption data is generally used for short-term load estimation. In this study, daily electrical energy consumption of Turkey in the four years of data were used. Short-term load prediction modeling has been carried out. In this modeling, past electrical load values and temperature values were used as input, and in order to increase the prediction accuracy, the characteristics of the days were categorized weekly and classified according to the seasons. Different Artificial Neural Network models have been created according to input data, weekly categorization, and season criteria. In the study, mean absolute percentage error values were calculated. Among the models developed with ANN, the best MAPE value was $2.51 \%$ and the worst MAPE value was $4.48 \%$. When the season criterion is added, the MAPE value is more successful.

\section{ARTICLE INFO}

\section{Research article}

Received: 19.11 .2020

Accepted: 19.03.2021

Keywords:

artificial neural

network,

short term electrical

load forecast,

time series modeling,

daily electric load

forecast

*Corresponding author

\section{Introduction}

Short-term electrical load estimation is important for power systems. To provide economic reliability to consumers, load estimation should be made meticulously [1]. Planning the transmission and distribution of electrical load increases reliability. Planning decisions are based on estimates known as spatial load. Load forecasts can also help managers with financial planning [2]. Planning electrical energy correctly is important for the economy. When planning ahead of the day, it helps to determine the working programs of the production sites [3]. Better forecasting enables more accurate planning, accurate investment in terms of performance, time, and cost. Forecasting studies for the future are not an easy process. There are many electrical load estimation studies. However, it is not healthy to use them in any country's estimation request. It is not possible to use a general model for the environment and environmental conditions for each country [4].

Electricity load estimation has great importance for the efficient operation of power plants. High error value in estimating the load value may cause to activate too many power units or may cause unnecessary use of reserves and this leads to waste [5]. Many operating decisions are determined by load estimates. The production capacity, distribution planning and maintenance plan of the business depend on the load forecast decision [6]. Electric load demands should be estimated as accurately as possible to make planning studies healthier. It is very important for decision makers to estimate electricity demand in the energy sector with minimum error. Making the planning of work, sharing the load, and determining the best group, making the production in the most economical way increases the importance of short-term electrical load estimation. Electric load estimates are made to make a good system planning.

Electricity estimation is examined in three classes. Short term (hourly, daily and weekly), medium term (monthly, quarterly) and long term (year or more than a year) [7]. Short-term load forecasts usually include estimates to be made from the hourly forecast up to one week. Short-term load estimates are required for planning functions such as power generation 
coordination. This coordination can be used to create hourly schedules of production resources, thereby minimizing operating costs for energy power systems [5]. Short term electrical load estimation is essential for control and planning of the power system. Long and medium term electrical load prediction is used to determine the capacity of the generation, transmission and distribution system [8]. Short term load forecast plays a very important role in improving the economy. It becomes more important with the development of power markets [9].

There are different studies in the literature for the purpose of performing electrical load estimation. In the literature research, it was investigated that artificial neural network gave successful results in estimation processes. Es et al. (2014), by using ANN, conducted the study of Turkey's net energy demand forecast. In this study, ANN and prediction models, which are widely used in the energy field, were examined. Regression and time series models were developed, and comparisons were made with the ANN model to evaluate the success of the prediction study and to measure its performance. Time series error rate was calculated as 3.21\% and ANN error value as $1.75 \%$. As a result of the analyzes and comparisons, ANN technique has been determined to make more successful predictions [10].

Yavuzdemir et al. (2014) has made Turkey's short-term electricity demand study. Three different methods were used. Fuzzy logic, time series and regression methods are discussed. Performance evaluation was made by comparing the average absolute error rates of the methods. Time series error rate is $2.75 \%$, fuzzy model error rate is $4.81 \%$ and linear regression model error rate is $7.64 \%$. The methods used in applications have yielded successful results [11].

Kaysal et al. (2015) conducted a hybrid (ANN and Regression) model study for load estimation. Artificial neural networks and regression methods are used. What makes the study different is that it has been predicted at micro scale and a hybrid system has been used. The MAPE value was calculated as $6.67 \%$ in the ANN model, $7.49 \%$ in the regression model and 5.26\% in the hybrid model. In this study, the hybrid model gave more successful results [12].

Estimation of unbalance cost due to demand prediction errors using artificial neural network study was conducted by Tümer et al. (2018). The imbalance loss caused by electricity has been estimated. ANN model is used. Load estimation study of Niğde province has been handled. Two different methods are used. Methods, nonlinear trend analysis moving average methods and artificial neural network backpropagation algorithm. The correlation coefficient value by using ANN was 0.78 for the test data set. It was determined that the best results were obtained with the ANN model [13].
Estimation of the electricity consumption of Turkey through artificial neural networks study was conducted by Tümer et al. (2016). ANN was used in this study. The high correlation between estimated electricity load consumption and actual load consumption has reached up to 0.95 . Therefore, ANN has been successful in electricity load estimation. In this study, it was seen that ANN is very good at predicting [14].

In the study carried out by Haliloğlu et al. (2018), the electricity loads, and daily totals taken from the EPIAS website at the hourly frequency were taken. Model is created by using least squares method for prediction model. According to the model, daily electricity load estimation study has been made for the period January - April 2018. When electricity demand is brought to the monthly frequency, there is a deviation of $1.64 \%$ for January, $1.49 \%$ for February, $1.34 \%$ for March and $1.30 \%$ for April. The success of shortterm electrical load estimates is directly proportional to the length of the data set used [15].

A short-term electrical load estimation study was carried out in Nigeria by Adepoju et al. In 2007 using ANN. Using the data used in the training, the electric load of the previous hour, the electric load of the previous day, the electric load of the previous week, the day and hour of that week, a 3-layer ANN was created. There are 3 layers, and these layers are called input layer, hidden layer and output layer. The input layer has 5 neurons. Hourly load estimation study has been done with past load value electrical load data. In this study, $2.54 \%$ absolute mean error (MAE) value was obtained. As a result of the obtained results, the applicability of ANN for short term electric load estimation has been approved [16].

Short term load prediction study was carried out by Fan and Hyndman in 2011. The proposed model for estimating the relationship between load demand and independent variables such as calendar and temperature is the semi-parametric regression model. Load estimation study from half an hour prediction to seven days prediction has been conducted for Australian National Electricity Market power systems. In the study, 2.81\% MAPE value was obtained [17].

Lee and Tong conducted China's electrical load prediction study using the gray model supported by genetic algorithm in 2011. The gray prediction model can lead to large prediction errors. In order to minimize such errors, a gray model was created in this study using a genetic algorithm. 26.21\%, $20.23 \%, 20.23 \%$ and $27.76 \%$ MAPE values were achieved in 2004-2007, respectively [18].

Himanshu and Lester developed an experimental model based on regression analysis in 2008 and made the electrical load estimation study of Jordan. Its largest unit is around $120 \mathrm{MW}$. The approximate error value is $6 \%$ and represents a very significant difference [19]. 
Electric load demands should be predicted as accurately as possible to make planning studies better. Reliable and accurate estimates are needed for the future. The most economical way of electricity generation is important for distribution companies and consumers. The aim of this study is to minimize the error in electrical load estimation. It is aimed to minimize the error rate by handling daily electrical load data.

\section{Material method}

Daily, hourly, or weekly electricity consumption data is used in short-term load estimation. In this study, daily electrical load data and feed forward backpropagation algorithm of artificial neural network are used. Daily electricity consumption in Turkey in the four years of data are used. Daily energy consumption data of 2016, 2017 and 2018 will be used in the training of artificial neural network. Daily energy consumption data for 2019 was handled as test data. In addition, the seasonal criterion is discussed in application to investigate the importance of electrical energy consumption in seasonal conditions. Daily electricity load data for years were examined. It has been found that there are differences in the daily electrical load data and similarities in the load data and accordingly, the feed forward backpropagation algorithm has been applied by categorizing the data.

\subsection{Data Set}

Data in the short-term electricity load estimation study belongs to 2016, 2017, 2018 and 2019. Load data were obtained from open access EPIAS website [20]. Temperature data were obtained from the open access Turkey weather websites [21]. Daily load data for 2016, 2017 and 2018 were used in the training of ANN. Daily electricity load data for 2019 was used for model testing. First of all, charts of daily electricity load data are examined by years. In the data used in the developed model, the data of the weeks with the public holiday were removed from the dataset. The electricity load data for the remaining 303 days of the year were estimated. In Figure 1, the daily electricity load amount graph for 2016, 2017, 2018 and 2019 were given.

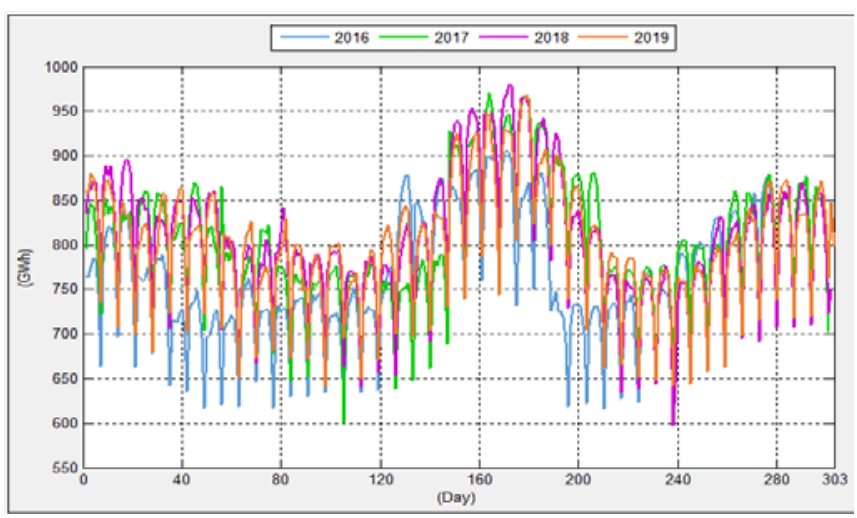

Figure 1. Daily electricity load amount graphic for 2016, 2017, 2018 and 2019.

In Figure 2, the average graph of the daily electricity load data by years was given.

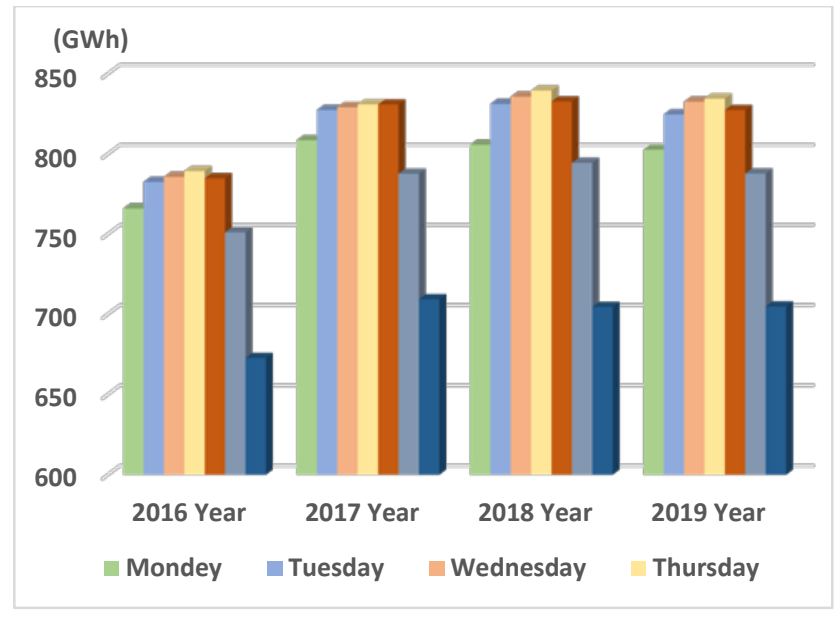

Figure 2. Average graph of daily electric load data by years.

When the graphs given in Figures 1 and 2 are analyzed, it is seen that the electricity load data for Tuesday, Wednesday, Thursday and Friday are similar. It is the days when the daily electricity load data falls on the weekend and becomes the lowest on Sunday. Fall and rise of load data on Saturday, Sunday and Monday are different. On weekdays, Monday has a lower load consumption than other days. On Tuesday, Wednesday, Thursday and Friday, the load values have an almost equivalent load.

Daily electricity load data for 2016, 2017, 2018 and 2019 are grouped by seasons. Table 1 contains grouping according to the seasons. When Table 1 is analyzed, the highest load consumption occurred in summer. The least load consumption occurred in the spring season. When the electrical load consumption data for years are analyzed, it is seen that the seasonal factor has an important role in load consumption. 
Table 1. Comparison of daily electricity load data for years according to seasons.

\begin{tabular}{lcccc}
\hline Season & $\begin{array}{c}\text { Load Consumption } \\
\text { in 2016 (GWh) }\end{array}$ & $\begin{array}{c}\text { Load Consumption } \\
\text { in 2017 (GWh) }\end{array}$ & $\begin{array}{c}\text { Load Consumption } \\
\text { in 2018 (GWh) }\end{array}$ & $\begin{array}{c}\text { Load Consumption } \\
\text { in 2019 (GWh) }\end{array}$ \\
\hline Spring & 65363,42008 & 68393,82538 & 70126,25309 & 69991,54880 \\
Summer & 73689,86612 & 77602,41288 & 77908,35579 & 76836,94134 \\
Autumn & 65766,43777 & 70830,37170 & 70215,09600 & 70101,31634 \\
Winter & 70045,24512 & 73148,56772 & 73921,64717 & 73517,11743 \\
\hline
\end{tabular}

In Figure 3, the graph of the comparison of daily electricity load data for 2016, 2017, 2018 and 2019 by seasons is given.

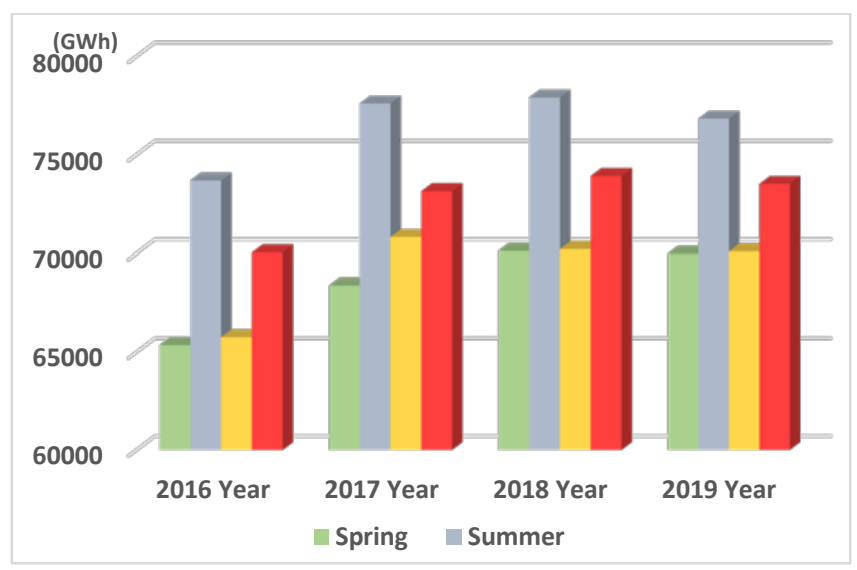

Figure 3. Comparison chart of daily electricity load data for years by seasons.

In this study, firstly, all of the load data are modeled without categorizing. Later, due to the similarities and differences of the load data, the data were divided into categories and applied to the model. Similarities of load data were taken into consideration in the categorization process. It was evaluated in a different category because the load data of Tuesday, Wednesday, Thursday and Friday were similar. The remaining days were evaluated in separate categories due to the change difference in load data.

Days of the week divided into categories in load estimates:

- Category 1: Tuesday, Wednesday, Thursday and Friday

- Category 2: Saturday

- Category 3: Sunday

- Category 4: Monday

Electricity market development report for 2016, 2017 and 2018 has been examined. In 2016, the highest electricity consumption was realized in Istanbul with $36.96 \mathrm{TWh}$. It corresponds to $17.39 \%$ of the total consumption [22]. In 2017, the highest electricity consumption was realized in Istanbul with 36.93 TWh. It corresponds to $17.39 \%$ of the total consumption [23]. The highest amount of electricity consumption in 2018 was realized in Istanbul with 40.45 TWh. It corresponds to $17.32 \%$ of the total consumption [24]. Considering the electricity consumption data by years, the highest consumption belongs to the city of Istanbul. The highest electricity consumption level is in Istanbul. That is why the temperature of Istanbul is discussed in this study. In this study, the load data of the previous week (t-7) of that day is considered as the past load value. For example, Sunday data was taken one week ago as the past load data of Sunday.

\subsection{Artificial Neural Networks}

Artificial Neural Network (ANN), which forms a sub-branch of artificial intelligence, was developed by being inspired by the working structure of the human brain [25]. Artificial neural network is a system developed through learning. In addition to learning, it has the feature of establishing a relationship between data [26]. The ANN can be trained with past data and use them to make forward predictions.

The data set obtained for the training of ANN is categorized according to the day and season. The data were used in training and testing ANN. Daily load data of 2016, 2017 and 2018 were used in the training of ANN, and daily electricity load data for 2019 was used for model testing. Neural Network Toolbox was used in MATLAB program to train ANN. Models were created with the feed forward back propagation algorithm. Temperature and past (t-7) electrical load values were used as input data in all models. For some models, the season is considered as input value. In the models where the season is considered as the input variable, the value 1 for the winter day, 2 for the spring day, 3 for the summer day, and 4 for the autumn day. Load data of the previous week (t-7) of that day is considered as the past load value. Using the obtained data, models consisting of single hidden layer and number of hidden neurons in the range $[2,20]$ were performed. In the studies, the error values are minimized by adjusting the weights in the network.

The data used in models developed for short-term electricity load prediction with ANN are shown in Table 2. 
Table 2. Data and data type used in ANN models.

\begin{tabular}{|c|c|c|c|c|c|}
\hline $\begin{array}{l}\text { ANN } \\
\text { Models }\end{array}$ & Data Type & $\begin{array}{c}\text { Day } \\
\text { Categorization }\end{array}$ & $\begin{array}{c}\text { Season } \\
\text { Input Data }\end{array}$ & $\begin{array}{c}\text { Past Load } \\
\text { Input Data(t-7) }\end{array}$ & $\begin{array}{c}\text { Temperature } \\
\text { Input Data }\end{array}$ \\
\hline Model 1 & All Days & No & No & Yes & Yes \\
\hline Model 2 & All Days & No & Yes & Yes & Yes \\
\hline Model 3 & $\begin{array}{l}\text { Tuesday, Wednesday, } \\
\text { Thursday, Friday }\end{array}$ & Yes & No & Yes & Yes \\
\hline Model 4 & $\begin{array}{l}\text { Tuesday, Wednesday, } \\
\text { Thursday, Friday }\end{array}$ & Yes & Yes & Yes & Yes \\
\hline Model 5 & Saturday & Yes & No & Yes & Yes \\
\hline Model 6 & Saturday & Yes & Yes & Yes & Yes \\
\hline Model 7 & Sunday & Yes & No & Yes & Yes \\
\hline Model 8 & Sunday & Yes & Yes & Yes & Yes \\
\hline Model 9 & Monday & Yes & No & Yes & Yes \\
\hline Model 10 & Monday & Yes & Yes & Yes & Yes \\
\hline
\end{tabular}

The MAPE values of the models consisting of single layer and hidden neurons in the range $[2,20]$ were calculated with ANN. The MAPE values of the developed models according to the number of hidden neurons are given in Figure 4. The best MAPE value of the models was obtained when the number of hidden neurons was 8 .

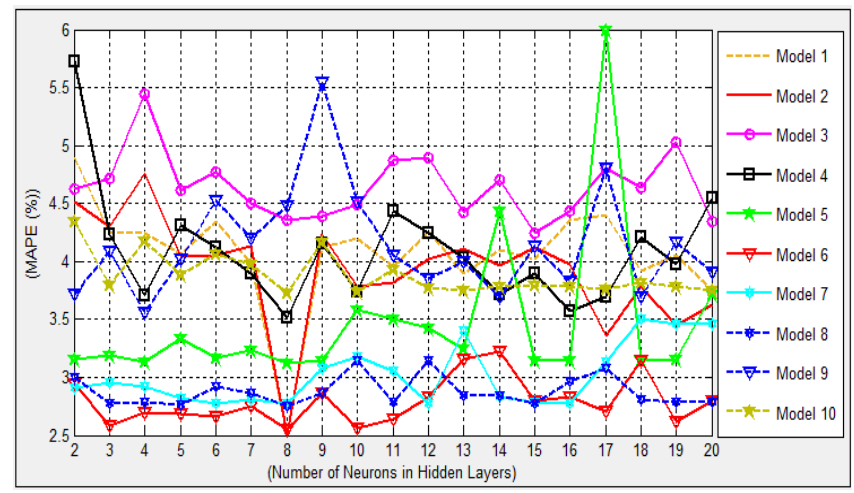

Figure 4. Comparison graph of MAPE values according to the number of hidden neurons of the developed models.

The best number of epochs for the model with 8 neurons in the hidden layer was found to be 1000 by trial and error. Table 3 includes the parameters used in ANN training.

Table 3. Parameters used in ANN training.

\begin{tabular}{ll}
\hline Algorithm & $\begin{array}{l}\text { Feed Forward Back Propagation } \\
\text { Algorithm }\end{array}$ \\
\hline Training function & TRAINGDX \\
Learning function & LEARNGDM \\
$\begin{array}{l}\text { Activation function } \\
\text { Number of layers }\end{array}$ & $\begin{array}{l}\text { TANSIG } \\
\text { Number of hidden layer } \\
\text { neurons }\end{array}$ \\
$\begin{array}{l}\text { Number of iterations } \\
\text { Learning coefficient }\end{array}$ & 8 \\
\hline
\end{tabular}

The model using temperature, past load input variables and estimated load output variable is shown in Figure 5.

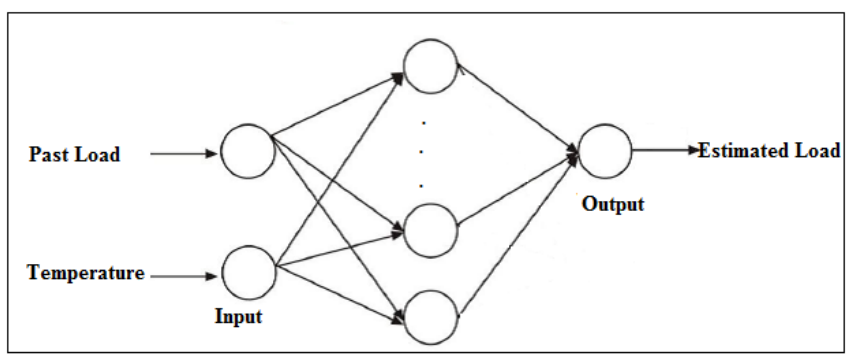

Figure 5. ANN model developed for the first application.

The model using temperature, past load and seasonal input variables and estimated load output variable is shown in Figure 6.

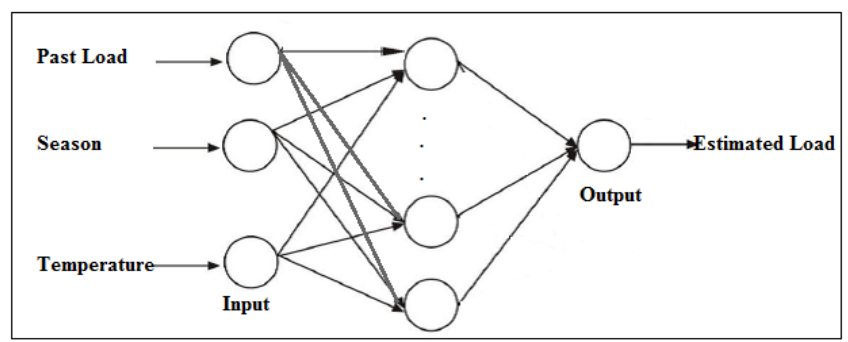

Figure 6. ANN model developed for the second application.

"Mean Absolute Percentage Error" was calculated in the developed models. In Equation 1, the MAPE calculation formula is applied.

$$
\begin{array}{r}
\text { Estimated Value }=E, \\
\text { Actual Value }=A, \\
M A P E=\frac{100}{n} \sum_{k=1}^{n}\left|\left(E_{k}-A_{k}\right) / A_{k}\right| .
\end{array}
$$




\section{Developed load forecast models}

Daily short-term electricity load and temperature values for 2016, 2017 and 2018 were obtained. These data were used in the training of the network. The daily short-term electricity load amount for 2019 has been calculated. Data on the weeks of public holidays are not processed. In MATLAB program, training was carried out using feed forward back propagation algorithm. After the network is trained, the test output data given as predicted by the network was compared with the actual values.

\subsection{ANN Models}

Temperature of the days and past electrical load data were used as input data in Model 1, 3, 5, 7 and 9. Temperature of days, season and past electrical load data are used as input data in Model 2, 4, 6, 8 and 10. The models were created using the estimated load output variable. Load data of the previous week's (t-7) was considered as the past load value. Output variable is the daily short-term electric load amount. In determining the seasonal input value, the value 1 for the day of the winter season, the value 2 for the day of the spring season, the value 3 for the day of the summer season, the value 4 for the day of the autumn season were used.

Figure 7 shows the graphical comparison of the estimated value of model with the actual values for all days of the week in the Model 1. In Model 1, the MAPE value was obtained as $2.53 \%$ between the actual electrical load values and the estimated electrical load values.

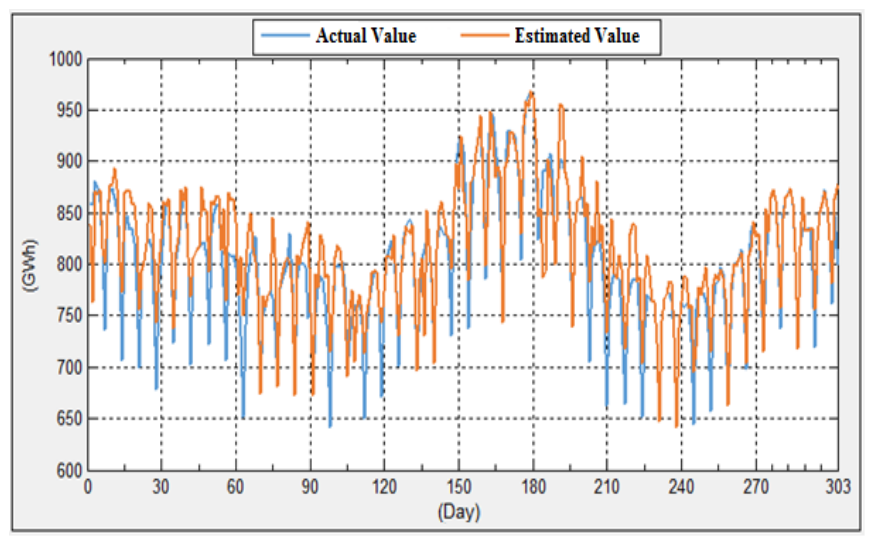

Figure 7. Graphical comparison of actual values and estimated values in the Model 1.

Figure 8 shows the graphical comparison of the estimated value of model with the actual values for all days of the week in the Model 2. In Model 2, the MAPE value was obtained as $2.51 \%$ between the actual electrical load values and the estimated electrical load values.

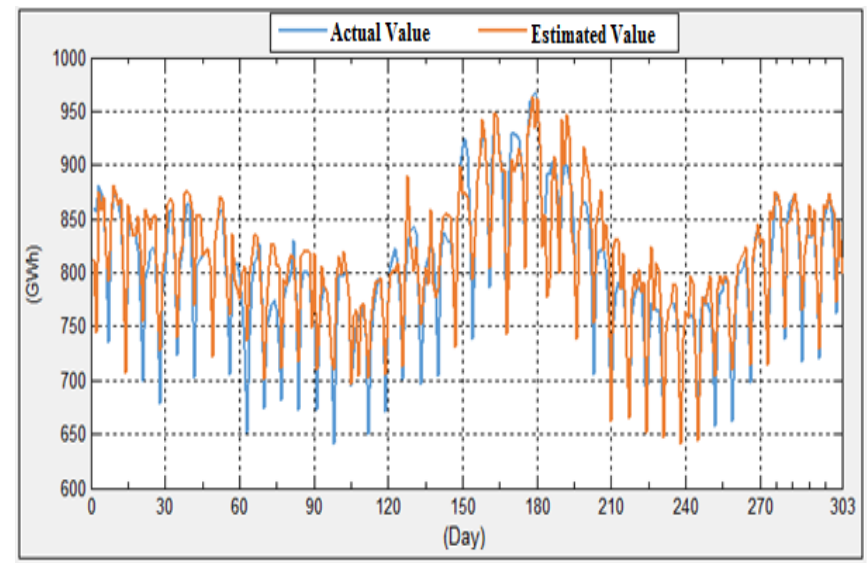

Figure 8. Graphical comparison of real values and estimated values in the Model 2.

Figure 9 shows the graphical comparison of the estimated value of model with the actual values in the Model 3 for Tuesday, Wednesday, Thursday and Friday. In Model 3, the MAPE value was obtained as $4.36 \%$ between the actual electrical load values and the estimated electrical load values.

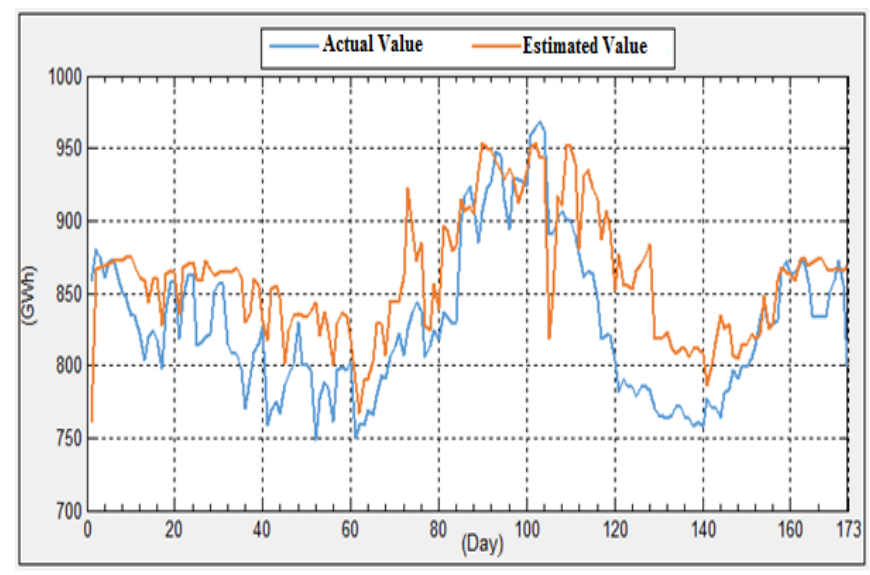

Figure 9. Graphical comparison of real values and estimated values in the Model 3.

Figure 10 shows the graphical comparison of the estimated value of model with the actual values in the Model 4 for Tuesday, Wednesday, Thursday and Friday. In Model 4, the MAPE value was obtained as $3.52 \%$ between the actual electrical load values and the estimated electrical load values. 


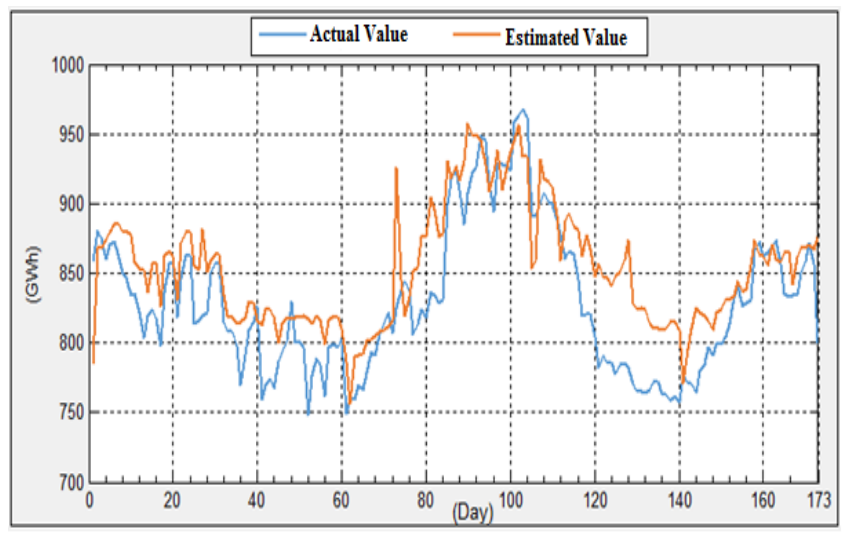

Figure 10. Graphical comparison of real values and estimated values in the Model 4.

Figure 11 shows the graphical comparison of the estimated value of model with the actual values in the Model 5 for Saturday. In Model 5, the MAPE value was obtained as 3.12 $\%$ between the actual electrical load values and the estimated electrical load values.

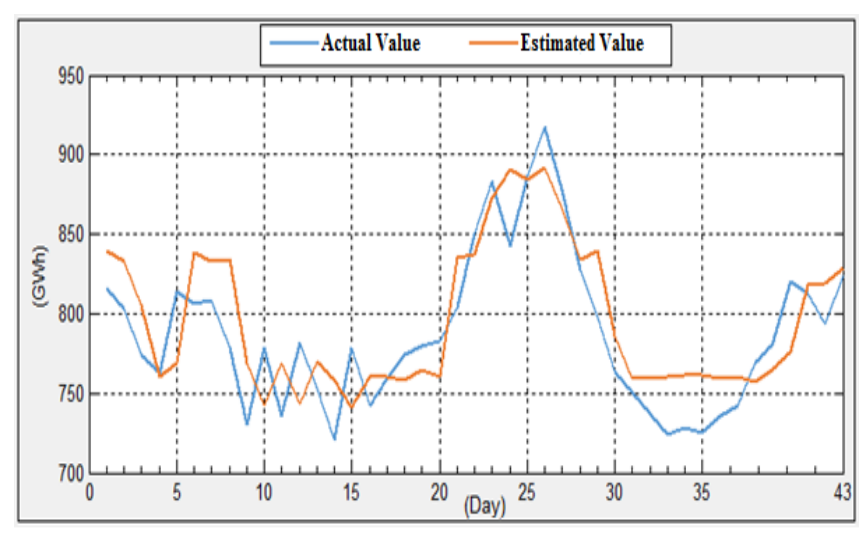

Figure 11. Graphical comparison of real values and estimated values in the Model 5.

Figure 12 shows the graphical comparison of the estimated value of model with the actual values in the Model 6 for Saturday. In Model 6, the MAPE value was obtained as 2.55 $\%$ between the actual electrical load values and the estimated electrical load values.

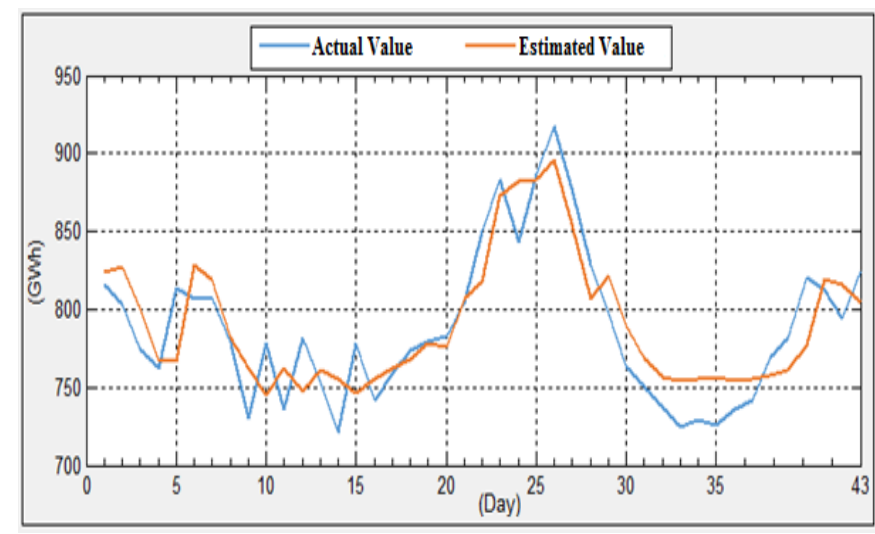

Figure 12. Graphical comparison of real values and estimated values in the Model 6.

Figure 13 shows the graphical comparison of the estimated value of model with the actual values in the Model 7 for Sunday. In Model 7, the MAPE value was obtained as $2.77 \%$ between the actual electrical load values and the estimated electrical load values.

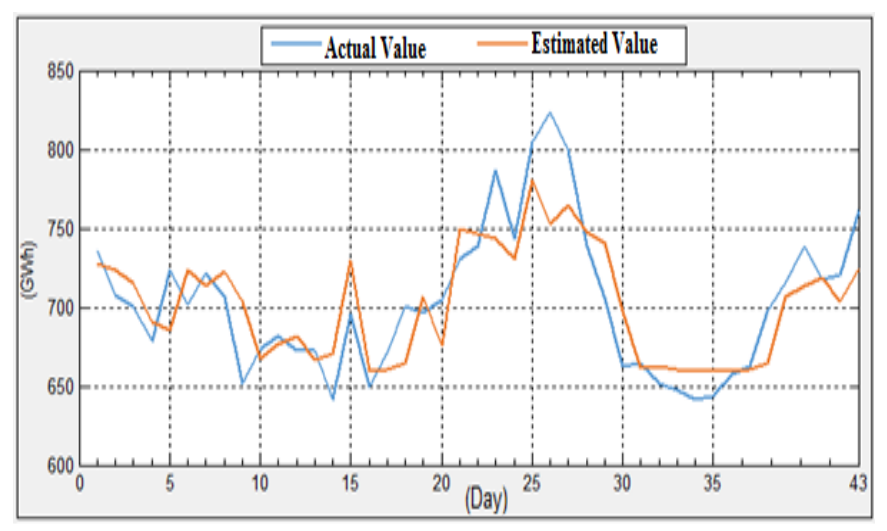

Figure 13. Graphical comparison of real values and estimated values in the Model 7.

Figure 14 shows the graphical comparison of the estimated value of model with the actual values in the Model 8 for Sunday. In Model 8, the MAPE value was obtained as $2.75 \%$ between the actual electrical load values and the estimated electrical load values. 


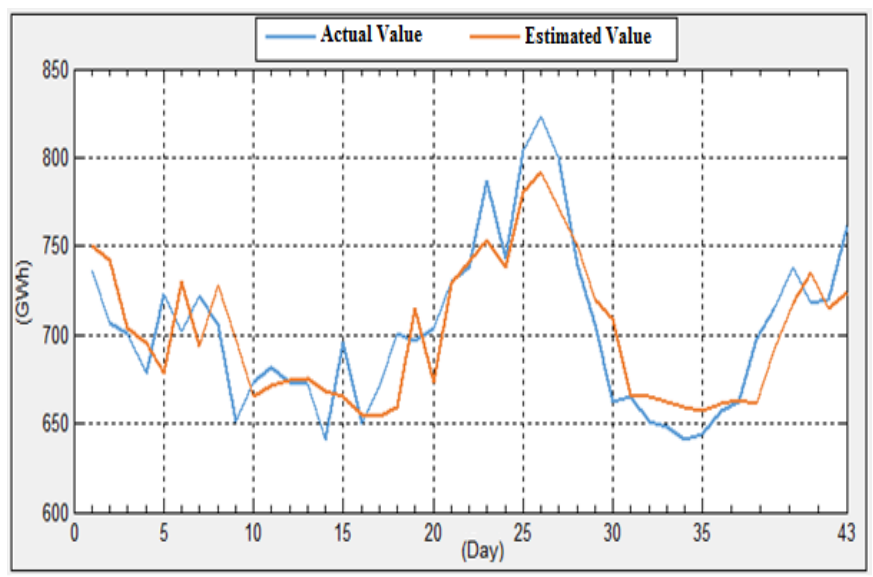

Figure 14. Graphical comparison of real values and estimated values in the Model 8.

Figure 15 shows the graphical comparison of the estimated value of model with the actual values in the Model 9 for Monday. In Model 9, the MAPE value was obtained as 4.48 $\%$ between the actual electrical load values and the estimated electrical load values.

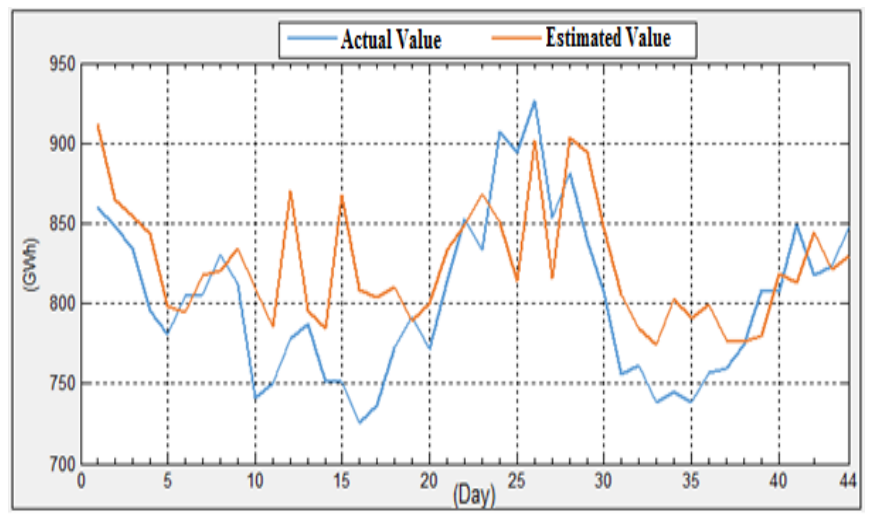

Figure 15. Graphical comparison of real values and estimated values in the Model 9.

Figure 16 shows the graphical comparison of the estimated value of model with the actual values in the Model 10 for Monday. In Model 10, the MAPE value was obtained as 3.73 $\%$ between the actual electrical load values and the estimated electrical load values.

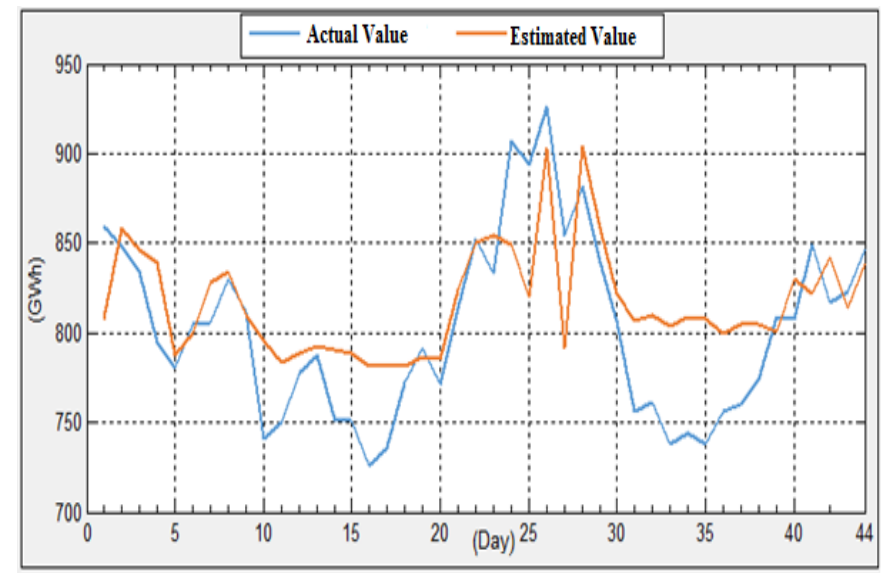

Figure 16. Graphical comparison of real values and estimated values in the Model 10.

\section{Results}

ANN has been used in this study for short term electrical load estimation. Feed forward back propagation algorithm is used as algorithm. Studies based on electric load estimation have been examined. The actual electrical load data and estimated electrical load data are compared.

Data must be obtained before making a forecast. Analysis of these data should be done well. Turkey's daily electricity consumption data are used as electrical load data. Load data for the years 2016, 2017 and 2018 were taken for training of ANN. Load data of 2019 was considered as test data. The effect of temperature on load consumption varies according to the seasons. Temperature is the most important factor in shortterm electrical load estimation. The temperature of İstanbul which is Turkey's most electricity consumption province was considered.

Models were created according to data entry and the number of hidden neurons with the feed forward back propagation algorithm. seasonal data was used in some models. Due to the similarities and differences of the load data, the data were categorized and models were created. Also an evaluation was made between models. MAPE value of the models is calculated.

The graph of the MAPE values of the models created by using the feed forward back propagation algorithm is given in Figure 17. Among the models developed with ANN, the best MAPE value was obtained as 2.51\% (Model 2). The addition of the season criteria has yielded a successful result. 


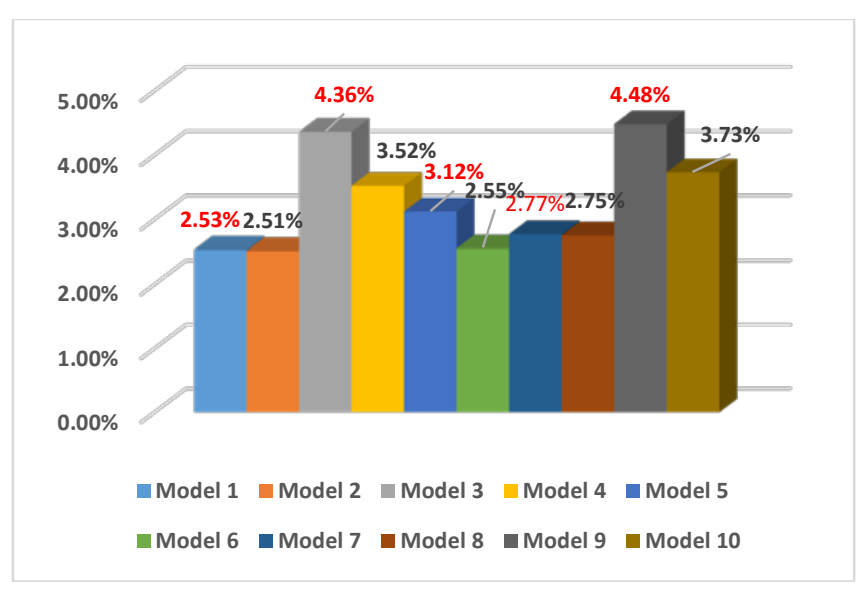

Table 4 shows the comparison of seasonal MAPE values of models developed with ANN. The red colored areas in the table show the worst MAPE values and the green colored areas show the best MAPE values. The best MAPE values were obtained in the winter season, and the worst MAPE values were obtained in the autumn and spring seasons.

Figure 17. MAPE values of models developed with feed forward back propagation algorithm.

Table 4. Comparison of seasonal MAPE values of models developed with ANN.

\begin{tabular}{lllll}
\hline ANN Model & $\begin{array}{l}\text { Spring MAPE } \\
\text { Value (\%) }\end{array}$ & $\begin{array}{l}\text { Summer } \\
\text { MAPE Value } \\
\text { (\%) }\end{array}$ & $\begin{array}{l}\text { Autumn MAPE } \\
\text { Value (\%) }\end{array}$ & $\begin{array}{l}\text { Winter MAPE } \\
\text { Value (\%) }\end{array}$ \\
\hline Model 1 & $3,14 \%$ & $2,00 \%$ & $2,52 \%$ & $2,35 \%$ \\
Model 2 & $3,10 \%$ & $2,33 \%$ & $2,51 \%$ & $2,11 \%$ \\
Model 3 & $5,40 \%$ & $2,85 \%$ & $5,97 \%$ & $2,81 \%$ \\
Model 4 & $3,13 \%$ & $3,23 \%$ & $4,97 \%$ & $2,64 \%$ \\
Model 5 & $3,94 \%$ & $2,35 \%$ & $3,08 \%$ & $3,20 \%$ \\
Model 6 & $2,75 \%$ & $1,79 \%$ & $2,87 \%$ & $2,63 \%$ \\
Model 7 & $2,89 \%$ & $3,59 \%$ & $2,93 \%$ & $2,62 \%$ \\
Model 8 & $2,84 \%$ & $2,55 \%$ & $2,34 \%$ & $3,49 \%$ \\
Model 9 & $6,86 \%$ & $4,12 \%$ & $4,59 \%$ & $2,82 \%$ \\
Model 10 & $3,65 \%$ & $3,79 \%$ & $5,27 \%$ & $2,52 \%$ \\
\hline
\end{tabular}

\section{Conflicts of interest}

The results of prediction of the electrical load studies in the literature are given in Table 5 . In this study, the best MAPE value was calculated as $2.51 \%$ with the ANN model. The past load has been obtained in accordance with the categorization. The categorization of the past load data and the handling of the seasonal input data enabled the MAPE value to give a successful result. It has been determined that the seasonal criterion has an important role in the estimation of the electrical load. In future studies, by using different algorithms, error values can be reduced to minimum levels, or successful results can be achieved by determining the factors affecting electrical load consumption in the input data and reducing the error rate. 
Table 5. Comparison of the MAPE values of the studies.

\begin{tabular}{|c|c|c|c|c|c|c|}
\hline Country & Year & The Data used & The Models Used & $\begin{array}{l}\text { MAPE } \\
\text { Value } \\
\text { (\%) }\end{array}$ & $\begin{array}{l}\text { Load } \\
\text { Estimated } \\
\text { Time }\end{array}$ & Reference \\
\hline Turkey & 2014 & $\begin{array}{l}\text { Past electrical load, } \\
\text { time zones during the } \\
\text { day, } \\
\text { temperature and } \\
\text { humidity, } \\
\text { meteorological data }\end{array}$ & $\begin{array}{l}\text { Levenberg - } \\
\text { Marquardt Model } \\
\text { Developed by } \\
\text { Backpropagation } \\
\text { Algorithm }\end{array}$ & $\% 7.52$ & Short Term & $\begin{array}{l}\text { (Var \& Türkay, } \\
\text { 2014) }\end{array}$ \\
\hline Turkey & 2015 & $\begin{array}{l}\text { One week prior load } \\
\text { data and seasonal } \\
\text { data }\end{array}$ & $\begin{array}{l}\text { ANN Model } \\
\text { Regression Model } \\
\text { Hybrid Model }\end{array}$ & $\begin{array}{l}\% 6,67 \\
\% 7,49 \\
\% 5,26\end{array}$ & Short Term & $\begin{array}{l}\text { (Hocaoğlu,Kaysal } \\
\text { \& Kaysal, 2015) }\end{array}$ \\
\hline Turkey & 2014 & $\frac{\text { Gross national product }}{\text { and energy demand }}$ & $\begin{array}{l}\text { Fuzzy Logic Model } \\
\text { Time Series Model } \\
\text { Regression Model }\end{array}$ & $\begin{array}{l}\% 4,81 \\
\% 2,75 \\
\% 7,64\end{array}$ & $\begin{array}{l}\text { Short Term } \\
\text { Yearly }\end{array}$ & $\begin{array}{l}\text { (Yavuzdemir \& } \\
\quad \text { Gökgöz, 2014) }\end{array}$ \\
\hline Australia & 2011 & Calendar, Temperature & $\begin{array}{l}\text { Semi Parametric } \\
\text { Regression Model }\end{array}$ & $\% 2,81$ & $\begin{array}{l}\text { Short Term } \\
\text { Hourly }\end{array}$ & $\begin{array}{l}\text { (Fan \& } \\
\text { Hyndman, 2011) }\end{array}$ \\
\hline
\end{tabular}

\section{References}

[1]. Var H., Türkay B. E., "Short term electric load forecasting using artificial neural networks", Elektronics - Computer and Biomedical Engineering Symposium, November 27-29, 2014, Bursa.

[2]. Hong T., "Short Term Electric Load Forecasting", Doctor of Philosophy, North Carolina State University, 2010.

[3]. Çevik H.H., "Short term electrical load forecasting of Turkey”, Master Thesis, Electrical and Electronics Engineering, Selcuk University Institute of Science and Technology, Konya, 2013.

[4]. Başoğlu B., Bulut M., "Development of a hybrid system based on neural networks and expert systems for shortterm electricity demand forecasting", Journal of the Faculty of Engineering and Architecture of Gazi University, 32.2, (2017), 575-583.

[5]. Akman T., Yılmaz C., Sönmez Y., "Analysis of electrical load forecasting methods", Gazi Journal of Engineering Sciences, 4.3, (2018), 168-175.

[6]. Fan S., Chen L., "Short-term load forecasting based on an adaptive hybrid method”, IEEE Transactions on Power Systems, 21.1, (2006), 392-401.

[7]. Hamzaçebi C., Kutay F., "Electric consumption forecasting of Turkey using articial neural netwoorks up to year 2010", Gazi University Journal of
Engineering and Architecture Faculty, 19.3, (2004), 227-233.

[8]. Lee K. Y., Cha Y. T., Park J. H., “ hort-term load forecasting using an artificial neural network", IEEE transactions on power systems, 7.1 (1992) 124-132.

[9]. Nie H., Liu G., Liu X., Wang Y., "Hybrid of ARIMA and SVMs for short-term load forecasting”, Energy Procedia, 16, (2012), 1455-1460.

[10]. Es H., Kalender F.Y., Hamzaçelebi C., "Forecesting the energy demand of Turkey by artificial neural network", Gazi University Journal of Engineering and Architecture Faculty, 29.3, (2014), 495-504.

[11]. Yavuzdemir M. Y., Gökgöz F.T.D, "Short-term gross annual electriciy demand forecast in Turkey", Master Thesis, Ankara University Institute of Social Sciences, Department of Business Administration, Ankara, 2014.

[12]. Kaysal K., Kaysal A., Hocaoğlu F.O., "Hybrid Model for Load Forecasting (ANN and Regression)”, Afyon Kocatepe University, Faculty of Engineering, Department of Electric Engineering, Turkey, (2015), 33-39.

[13]. Tümer Abdullah Erdal, Yavuz Cankat, Koçer Sabri (2018). Estimation of Unbalance Cost Due To Demand Prediction Errors Using Artificial Neural Network. Selçuk University Technology Faculty SelçukTechnical Journal, Special Issue 2018 (ICENTE'17), 27-37. 
[14]. Tümer A.E., Koçer S., Koca A. (2016, November). Estimation of the electricity consumption of Turkey trough artificial neural networks. In 2016 IEEE 17th International Symposium on Computational Intelligence and Informatics (CINTI) (pp. 000315000318). IEEE.

[15]. Haliloğlu E.Y., Tutu B.E., "Short-term electricity power demand forecasting for Turkey", Journal of Yasar University, 13.51, (2018), 243-255.

[16]. Adepoju G.Y., Ogunjuyigbe S.O.A., Alawode K.O., Application of neural network to load forecasting in Nigerian electrical power system, Ladoke Akintola University of Technology Nigeria, The Pacific Journal of Science and Technology, vol. 8, pp., (2007), 68-72.

[17]. Fan S., Hyndman R.J., Short-term load forecasting based on a semi-parametric additive model, Monash Univ., (2011), Clayton, Australia, Augus.

[18]. Lee Y.S., Tong L.I., Forecasting energy consumption using a grey model improved by incorporating genetic programming, Energy Conversion and Management, (2011), 52 : 147-152.

[19]. Himanshu A.A., Lester C.H., Electricity demand for Sri Lanka: a time series analysis. Energy, (2008), 33, 724739.
[20]. “EPIAS Transparency Platform”, [Online]. Available: [https://seffaflik.epias.com.tr], [Accessed: September 15, 2019].

[21]. "Weather Turkey”, [Online]. Available: https://www.havaturkiye.com. [Accessed: September 15, 2019].

[22]. "Electricity market 2016 market development report", T. C. Energy Market Regulatory Authority, Ankara, (2017).

[23]. "Electricity market 2017 market development report", T. C. Energy Market Regulatory Authority, Ankara, (2018).

[24]. "Electricity market 2018 market development report", T. C. Energy Market Regulatory Authority, Ankara, (2019).

[25]. Zontul M., Yangin A., "Data Mining on education publishing sector by artificial neural network tecniques”, Aurum Journal of Engineering Systems and Architecture, 1.2, (2017), 1-15.

[26]. Kılıç G., "Refectory Daily demand forecast using artificial neural networks", Master Thesis, Pamukkale University Institute of Science, Denizli, 2015. 